\title{
Harrodian instability in decentralized economies: an agent-based approach
}

\author{
Emanuele Russo*1 \\ ${ }^{1}$ EMbeDS and Institute of Economics, Scuola Superiore Sant'Anna, Pisa (Italy)
}

\begin{abstract}
Harrodian instability emerges in post-Keynesian models because of the cumulative feedback between demand and investments. This paper presents a novel approach to deal with Harrodian instability. The main contribution is methodological and lies in the different theoretical mechanism adopted to avoid unstable dynamics. While the common approach relies on aggregative investment functions, we emphasize the role of heterogeneity in expectations as a stabilization device. We introduce a small-scale agent-based version of the so-called neo-Kaleckian model. The model features a parsimonious microfoundation of investment decisions. Agents have heterogeneous expectations about demand growth and set their investment expenditures in a decentralized way. Interactions occur through demand externalities.

We present results for different scenarios. First, when heterogeneity is ruled out, Harrodian instability is shown to emerge as for the aggregate model. Instead, when heterogeneity is accounted for, a stable dynamics with endogenous fluctuations arises. At the same time, in this second scenario, all the Keynesian implications are preserved, including the presence of macroeconomic paradoxes. Sensitivity analysis confirms the general robustness of our results and the logical consistency of the model.
\end{abstract}

Keywords Harrodian Instability · Agent-Based Models · Coordination Failures · Heterogeneous Expectations.

JEL classification E03 $\cdot$ E12 $\cdot$ E27

\footnotetext{
*Email: emanuele.russo@santannapisa.it. Address: Institute of Economics, Sant'Anna School of Advanced Studies, Piazza Martiri della Libertá, 33-56127 Pisa, Italy
} 


\section{Introduction}

In light of the Great Recession, post-Keynesian theory has gained renewed popularity given the importance ascribed to aggregate demand and income distribution. Nevertheless, macro models in this tradition still face some important theoretical puzzles. Among them, the emergence of Harrodian instability (H-I) is certainly one of the most relevant. H-I, as originally stated in (Harrod, 1939), arise when moving from a static Keynesian model with exogenous investment rates to a dynamic framework in which investments have a capacity-creating effect. The main intuition is that firms, in response to a demand shock, will increase (or decrease) their investment rates in order to adjust their capital stock to the new level of demand. However, as investments are a key component of aggregated demand, this will further amplify the initial shock, driving the economy away from the equilibrium.

This paper studies the emergence of H-I in the so-called neo-Kaleckian (N-K) model (Rowthorn, 1981; Dutt, 1984) and presents a novel approach to deal with instability adopting an agent-based methodology. More specifically, we build a simple agent-based version of the N-K model with decentralized investment decisions. ${ }^{1}$ Agents are assumed to modify their expectations about future demand in an adaptive way and heterogeneity is introduced by idiosyncratic shocks. In such context, we address some important questions concerning: (i) the impact of heterogeneity, learning and adaptation upon the stability properties of the model; (ii) the nature of growth, whether it is still demand-driven or not; (iii) the presence of macroeconomic paradoxes (i.e. the paradox of thrift and the paradox of costs); (iv) the characteristics of the process governing the evolution of aggregate capacity utilization.

Solving the instability problem would entail greater consistency of the model allowing researchers to make more robust inference and policy analyses. This is why many works have been focusing on H-I (cf. the literature review in Section 2.2). As a matter of fact, the common approach to deal with H-I so far relies on modifications of the aggregate investment function (see e.g. Lavoie, 1995; Allain, 2015). Many of those efforts, however, have been criticized from different angles and there is still an open debate on how to consistently cope with H-I (Hein et al., 2011, 2012). At the same time, no systematic efforts have been made to adopt a more granular perspective and to investigate the role of heterogeneous expectations. Here we try to fill this gap by relying on parsimonious agent-based microfoundations of expectation dynamics and investment decisions. ${ }^{2}$

The agent-based approach is well suited to our purposes. This is because of the great flexibility of agent-based models (ABMs) which entails the possibility to study coordination problems among agents exhibiting different degrees of rationality. More generally, ABMs describe the economy as a complex evolving system whose aggregate dynamics emerges as a result of decentralized interactions among boundedly rational, heterogeneous agents. ${ }^{3}$ These features are directly related to the problem

\footnotetext{
${ }^{1}$ For large-scale Kaleckian ABMs see Setterfield and Budd (2011); Gibson and Setterfield (2018)

${ }^{2}$ Similar efforts have recently been made in relaxing some assumptions of DSGE models to incorporate heterogeneity (Massaro, 2013) and interactions (Guerini et al., 2018).

${ }^{3}$ Examples of macro ABM can be found in: Delli Gatti et al. (2010), Ashraf et al. (2017), Dawid et al. (2014), Riccetti et al. (2015), Riccetti et al. (2016), Salle et al. (2013), Seppecher and Salle (2015), Dosi et al. (2010, 2013,
} 
of H-I. In fact, as it will be argued (cf. Section 2.1), H-I emerges as a coordination failure when firms use adaptive expectations to forecast future demand growth. In particular, H-I originates from entrepreneurs inability to internalize demand externalities associated with new investments. ${ }^{4}$

Simulation results reveal some interesting patterns. As a first exercise, we simulate our economy removing heterogeneity and show that results are symmetrical to the aggregate N-K model, i.e. H-I emerges when firms are allowed to adapt their expectations. Then, we introduce idiosyncratic random prediction errors to demand expectations. In this second scenario aggregate dynamics becomes stable. The evolution of national capacity utilization, consistently with the empirical evidence (Nikiforos, 2016), is described by an I(1) process which do not exhibit any strong deterministic trending behaviour. ${ }^{5}$ At the same time, the economy is shown to preserve all the features found in Keynesian growth models, including the endogeneity of utilization rates and the presence of the paradoxes of thrift and costs. Since prediction errors are transitory, expectations are still linked to the evolution of demand, thus, avoiding the possibility of systematic forecasting mistakes. Differently from the baseline N-K model, expectations will tend to gravitate around the trend value of demand. However, our results suggest that purely mechanical adaptive adjustments cannot be sustained in the model whereas some idiosyncratic biases are needed in order to get a stable macrodynamics. In a complex environment characterized by strong interactions among agents (i.e. demand externalities in our specific case), departures from more rational behaviours appear to curb unstable tendencies.

The intuition underlying these results is rather simple: when heterogeneity is introduced, optimistic firms will coexist with pessimistic ones. Investment decisions cease to be symmetrical and uni-directional. As a consequence, in response to a shock, entrepreneurs will not coordinate anymore towards ever-rising (-decreasing) investment levels.

Considered the simple nature of the model, the main contribution of this work remains methodological rather than descriptive. We stress the crucial role played by heterogeneity and individual biases in stabilizing the system as they can break self-reinforcing patterns of bad coordination. More efforts should be devoted to the implementation of these features in post-Keynesian models. Finally, well in tune with the works of Keynes himself, they also show the importance of complexity-based microfoundations which are able generate intriguing macroeconomic phenomena as emergent properties of the system.

The reminder of this paper is organized as follows: Section 2 discusses H-I in the standard N-K model and presents an overview of the existing literature; Section 3 introduces the model; results and sensitivity tests are reported in Section 4; finally, Section 5 concludes.

2015, 2017); Lamperti et al. (2018); Dosi et al. (2019b, 2020b), Caiani et al. (2016) and Popoyan et al. (2017). For a detailed review of the literature see Fagiolo and Roventini (2012, 2017).

${ }^{4} \mathrm{~A}$ large literature has investigated coordination mechanisms and failures (see e.g. Leijonhufvud, 1976; Cooper and John, 1988; Howitt, 2006a,b). For instance, New Keynesian models have incorporated a game theoretic framework to deal with demand externalities (Diamond, 1982; Blanchard and Kiyotaki, 1987).

${ }^{5}$ Integrated processes display a path-dependent dynamics as shocks accumulate persistently over time. Russo et al. (2019) present empirical evidence in favour of I(1)processes in macro time series. 


\section{Literature review}

The so-called neo-Kaleckian model, originally presented in Rowthorn (1981) and Dutt (1984), has gained increased popularity among heterodox scholars. ${ }^{6}$ Part of its success is due to the simple linear structure adopted, which overcomes some theoretical problems found in the first generation of post-Keynesian growth models (Kaldor, 1957; Robinson, 1956). A famous extension (Bhaduri and Marglin, 1990), introduced the possibility to study the links between growth and functional distribution under various demand regimes.

Harrodian instabilty in the N-K model takes the form of ever-rising (or ever-falling) rates of capacity utilization (Hein et al., 2011, 2012). This is clearly in contrast with what observed in real economies as capacity utilization rates, over sufficiently long time spans, fluctuate around some stable average values exhibiting no deterministic trends.

In light of H-I, various scholars have proposed different stabilization mechanisms. The aim of this section is, first, to present a formal discussion of $\mathrm{H}-\mathrm{I}$ in the N-K setting and, second, to review the main approaches to tackle the instability problem.

\subsection{Harrodian instability in the baseline model: a coordination failure}

The baseline N-K model is composed by three difference equations: ${ }^{7}$

$$
\begin{gathered}
g i_{t}=\frac{I_{t}}{K_{t}}=g^{e}+\gamma_{u}\left(U_{t-1}-u_{n}\right) \\
g s_{t}=\frac{S_{t}}{K_{t}}=s_{p} R_{t} \\
R_{t}=\frac{m U_{t}}{v}
\end{gathered}
$$

Equation (N-K 1) is the investment function. Capital accumulation $(g i)$ is assumed to be affected by an exogenous thrift $\left(g^{e}\right)$ and by discrepancies between lagged capacity utilization $U$ and the targeted level $u_{n} \cdot{ }^{8}$ As pointed out in Committeri (1986), the term $g^{e}$ has to be interpreted as the "animal spirits" component, representing expectations about long-run demand growth. Intuitively, when capacity is utilized at the desired level $\left(U=u_{n}\right)$ entrepreneurs will invest just to accommodate future expected demand movements. Target utilization $\left(u_{n}\right)$, in this simple version, is assumed to

\footnotetext{
${ }^{6}$ The N-K model has been extended along several dimensions including: money and finance (Hein, 2007; Hein and Van Treeck, 2010), autonomous demand components (Allain, 2015), trade and open economies (Blecker, 1999, 2011), environmental innovations (Luìs et al., 2020). Moreover, it has been widely used for empirical applications to test the relationship between income distribution and growth (see e.g. Stockhammer et al., 2009; Hein and Vogel, 2008).

${ }^{7}$ The model is presented in discrete time for the sake of comparison with the agent-based version developed in Section 3.

${ }^{8}$ Given the focus on instability problems, we use the functional form presented by Hein et al. (2011). The parameter $\gamma_{u}$ regulates the strength of capacity adjustments, thus, representing firms responsiveness to situation of over- and under-utilization. For the sake of simplicity, the equation includes neither the realized profit rate nor the profit share. We therefore exclude the possibility of profit-led regimes.
} 
be exogenous and less than $100 \%$. In tune with the empirical evidence (Steindl, 1952), firms want to keep a portion of idle capacity in order to match unanticipated demand flows.

Equation (N-K 2) is the dynamic version of the standard Cambridge saving function (cf. Pasinetti, 1962, for a general presentation of the saving equation). When workers consume all their income, the growth rate of savings $(g s)$ is given by the profit rate $R$ times capitalists propensity to save $\left(s_{p}\right)$.

Finally, Equation (N-K 3) is an accounting identity implicitly derived from the assumption of a simple mark-up pricing rule. It links the realized rate of profit $(R)$ to: the gross profit margin $(m)$, the capital to capacity ratio $(v)$ and the utilization of capacity $(U)$. By imposing the long run equilibrium condition $g i=g s=g^{*}$, and by dropping time subscripts, the steady-state level of capacity utilization can be obtained:

$$
U^{*}=\frac{g^{e}-\gamma_{u} u_{n}}{s_{p} m / v-\gamma_{u}}
$$

At the steady state, in absence of technical change, total output and employment grow at a constant rate. The primary source of income growth are entrepreneurs animal spirits since they drive investments and capital accumulation.

In order for the solution to be stable, the so-called Keynesian stability condition is imposed. It requires the accumulation function to be less steep than the saving one. Loosely speaking, investments must not be too sensitive to variations in the utilization rate, as it was the case in Keynes short-run theory of income determination. In mathematical terms this amounts to:

$$
s_{p} r_{n} / u_{n}>\gamma_{u}
$$

Two important features of the equilibrium just obtained must be emphasized:

- $U^{*}$ is endogenous and does not coincide, if not by chance, with the target $u_{n}$. Demand conditions play a central role in determining utilization of productive resources.

- $\frac{\partial U^{*}}{\partial m}<0$ and $\frac{\partial U^{*}}{\partial s_{p}}<0$. The model implies the paradox of thrift and that of costs. A positive shock in the propensity to save, instead of promoting investments, will bring about lower utilization rates and capital accumulation because of the fall in aggregate expenditure. Symmetrically, a rise in the gross profit margins (i.e. a fall in the wage share), contrary to the standard intuition, will have detrimental effects on growth, capacity utilization and employment. Wages are indeed both a cost for firms and an important component of aggregate demand.

Such conditions make growth unambiguously demand-led. In discussing different solutions to H-I we will always take these two implications as benchmarks for comparisons.

So far, however, the expectation term is an exogenous parameter. In addition to this, the obtained equilibrium requires expectations to be continuously unfulfilled in order to be sustained. The steady-state prediction error can be computed from Equation (N-K 1):

$$
g^{*}-g^{e}=\gamma_{u}\left(U^{*}-u_{n}\right)
$$


Hence, the endogeneity of $U$ arises from a permanent collective failure to anticipate demand evolution. Entrepreneurs have to keep their forecasts fixed notwithstanding their sales steadily grow at a different rate. It seems more realistic instead to assume that, in the medium run, firms try to revise expectations adaptively. This implies a fourth differential equation:

$$
\dot{g}^{e}=\theta\left(g^{*}-g^{e}\right)
$$

The expectation term $g^{e}$ is now endogenized. Since $g^{e}$ refers to the expected trend of demand, the adjustment is generally assumed to occur slowly, entailing a relatively small $\theta$. Once augmented with the adaptive learning equation (N-K 4) the only possible equilibrium solution implies:

$$
U^{*}=u_{n} \quad \text { and } \quad g^{*}=g^{e}
$$

Notice that the endogeneity of $U$ is now lost since, at the equilibrium, utilization of capacity must be at the desired level. Furthermore, such new equilibrium is not stable anymore. ${ }^{9}$ Intuitively, let us suppose that a positive demand shock drives the economy away from the balanced growth path to a state with: $U>u_{n}$. Entrepreneurs will respond to over-utilization by increasing the speed of investment (cf. Eq. (N-K 1)). This, in turn, lead to higher income growth. Expectations will slowly adjust to the new trend of demand. As a result, the investment function will shift upwards rising once again the growth rate of the economy. Cumulative feedbacks between revision of expectations and demand growth bring about ever-rising (ever-decreasing) levels of utilization. To put it differently, individual attempts to adjust capacity and expectations lead to aggregate instability. This is a typical coordination failure (Cooper and John, 1988). When evaluating new investments plans, agents only consider the private effect while they do not internalize the underlying demand externality. ${ }^{10}$ This is how Harrodian instability emerges in the N-K model.

The model presented so far is aggregative. The investment function is obtained for a representative firm. In this respect, the long run expectation $g^{e}$ constitutes a black-box. One can reasonably conjecture that it results from some microeconomic mechanisms which, nevertheless, are not sketched and cannot be grasped by focusing exclusively on aggregate equations. The purpose of this paper is to open the black-box, introducing a simple ABM microfoundation for investments. We will show how standard conclusions about H-I can be reverted in such new setting.

\footnotetext{
${ }^{9}$ Indeed, plugging Equation (N-K 4) into the equilibrium solution for $u$ we have: $\dot{u}^{*}>0$ if $u>u_{n}$ (and viceversa), i.e. deviations from the steady state are self-reinforcing. For a detailed mathematical discussion see (Allain, 2015).

${ }^{10}$ Differently from the standard definition (Cooper and John, 1988), the coordination failure associated to H-I does not imply convergence to a Pareto-dominated equilibrium. On the contrary, instability arises exactly because agents found themselves persistently out of the steady state (i.e. $U \neq u_{n}$ ). The system is continuously in motion. This is an important aspect which suggests that an ABM approach should be preferred to a game theoretic one.
} 


\subsection{Dealing with Harrodian instability: standard approaches and a pos- sible way forward}

Many authors have put forward different approaches to deal with H-I, i.e. they introduced various theoretical mechanisms to bring back stability and avoid an explosive dynamics of $U{ }^{11}$ Most of the attempts, have been primarily concerned with the identification of the so-called traverse mechanisms. These amount to convenient modifications of the aggregate equations to achieve, at the equilibrium, the consistency condition: $U^{*}=u_{n}$. A traverse mechanism slowly drives the economy towards the target utilization level, thus, allowing the model to move from the short- to the long-run.

Kaleckian authors have proposed a specific traverse in which the target rate of utilization slowly converges to the realized one (Lavoie, 1995; Dutt, 1997). According to them, $u_{n}$ becomes endogenous in the long run, being affected by past realizations of $U$. From a formal point of view the argument is correct. Once coupled with this mechanism, stability is restored as well as all the implications found in the canonical model. However, the whole adjustment has been severely criticized for lacking of an economic rationale (Palumbo and Trezzini, 2003; Shaikh, 2009; Skott, 2012). In fact, it implies a sort of unrealistic satisficing behaviour: firms will respond passively to situations with excess of (shortage of) capacity. They will simply modify targets instead of adjusting their capital stocks. Other specific assumptions such as economies of scale in production (Nikiforos, 2016) and conflicting claims between managers and shareholders (Dallery and Van Treeck, 2011) have been introduced to make Kaleckian arguments more solid. Although interesting, none of these solutions will be considered in our model. We indeed want to stress how, once heterogeneity in expectations is accounted for, neither satisficing behaviours nor other specific hypothesis are needed to rescue the N-K model from instability.

Marxian and Sraffian economists, on the other side, have put forward an opposite traverse mechanism. In their models the actual rate of utilization happens to gravitate around the target in the long run. This is ensured by an investment function which typically embeds a stock-flow adjustment à la Hicks (1950). Desired utilization remains an exogenous variable which coincides with the point of lower unit costs and is therefore merely affected by technical conditions (Kurz, 1986). Different stabilizing forces involve the role of monetary policy (Duménil and Lévy, 1999), the retention ratio (Shaikh, 2009) and autonomous expenditures (Lavoie, 2014; Allain, 2015). A major implication is that in the long run both the paradox of costs and that of thrift do not hold anymore. Permanent variations in wages and in propensity to save only have a "level" effect since the degree of utilization is constrained to fluctuate around $u_{n}$. As argued in Palumbo and Trezzini (2003) and Hein et al. (2011), this process imposes strong requirements in terms of information and coordination among firms. In order for the system to gravitate around $u_{n}$, it seems necessary for entrepreneurs to act as a "body", undertaking investment decisions in a cooperative fashion. In our ABM we can explicitly test for this conjecture. Agents are allowed to continuously adapt expectations and investment rates in order to pursue their targets. Then, it is possible to investigate the emergent dynamics for $U$.

\footnotetext{
${ }^{11}$ The review proposed in this section aims to give only a broad picture of the literature. By no means it should be intended as fully-comprehensive. For large surveys on the topic see Hein et al. (2011) and Hein et al. (2012).
} 
As it will be discussed, the latter does not in fact imply gravitation around $u_{n}$. On the contrary, average aggregate utilization levels will still be endogenously determined.

The two main solutions discussed so far have radically different implications but share two important features. First, they are build upon an aggregate investment function and, as a consequence, cannot directly address problems of coordination. Second, they are both concerned with the determination of a long run equilibrium. Over a sufficiently large time horizon, system variables will oscillate in a neighborhood of their steady-state values.

Our approach, instead, draws upon the stream of literature that studies learning and expectation formation in complex environments (Gigerenzer and Todd, 1999; Dosi et al., 2003). In an inherently complex world, achieving rational expectations requires extremely high costs for computation and for gathering dispersed information. More realistically, individuals are assumed to hold heterogeneous beliefs and to rely on simple rule of thumbs and heuristics to form their decisions. This is in tune with early insights from cognitive psychology (Tversky and Kahneman, 1974). More recently, empirical evidence from survey data (Carroll, 2003; Pfajfar and Santoro, 2010) and lab experiments (Hommes et al., 2005; Hommes, 2011; Assenza et al., 2019) has further shown that agents exhibit strong departures from full rationality and that they use heterogeneous expectation rules to learn and to make forecasts about macroeconomic variables. Also, it has been pointed out that simple heuristics provide a better guidance for behaviour in highly uncertain environments than sophisticated computations (Gigerenzer and Todd, 1999). Those features have been largely incorporated in ABMs (Anufriev et al., 2013b; Dosi et al., 2020a) and in late generations of DSGE models (De Grauwe, 2012; Anufriev et al., 2013a; Massaro, 2013). Parallel attempts, to the best of our knowledge, are missing in the post-Keynesian setting. The strategy of this work is rather conservative: instead of fully developing expectation behaviour in the N-K model, we simply introduce idiosyncratic shocks in the adaptive rule adopted by agents. We then study how such a small deviation from the canonical model may affect its stability properties.

A second important departure from the common approach to cope with H-I regards the use of agent-based microfoundations of investment decisions, as opposed to the imposition of aggregative structural equations. This opens up the possibility to discuss aggregation dynamics and its impact on stability. An expanding body of literature is now concerned with the microeconomic origins of aggregate fluctuations (Gabaix, 2011; Acemoglu et al., 2012; Di Giovanni et al., 2014; Dosi et al., 2019a). For instance, Gabaix (2011) shows that in presence of skewed distributions of firms' size, micro shocks have large influence on macro volatility as they are not averaged out in the aggregation process. While Acemoglu et al. (2012) find a similar results when accounting for firms input-output linkages. Di Giovanni et al. (2014) provide further evidence in this direction using firm-level data for French companies. Finally, Dosi et al. (2019a) point out the larger relevance of firm-specific demand shocks over supply ones. 


\section{The Model}

The model is populated by $N$ firms (indexed by $i$ ) producing an homogeneous good that can be either consumed or accumulated as capital stock. At any point in time they formulate investment plans according to their demand expectations. As a result of investment decisions, the level of employment and aggregate demand is also determined. Total demand is then distributed to single firms according to an exogenous distribution of market shares and, consequently, firms learn about their sales and compute their rates of capacity utilization. Hence, companies' investments $(i)$ are the key control variables of the model affecting the state variables, i.e. respectively: employment $(l)$, capital stock $(k)$, production $(y)$ and capacity utilization $(u)$. The corresponding macro variables are then computed by linear aggregation.

Our agent-based version retains some of the simplifying assumptions present in the baseline N-K specification. First, there is no technical change: both the labour productivity coefficient and the capital-to-output ratio are exogenous and homogeneous across firms. Our focus is on heterogeneity in expectations (rather than in technologies) which drives differentials among agents in investments, capital stock and utilization rates. Second, the price level and the underlying distributional variables are constant. Hence, the gross profit margin $(m)$ and the wage rate $(w)$ are exogenous parameters. Finally, the supply of labour is infinitely elastic so that it poses no constraints on growth of demand and employment.

\subsection{The timeline of events}

Within each time step events proceed as follows:

1. Firms form expectations, set their investment expenditures and hire workers.

2. Wages are anticipated to workers.

3. Consumption plans are formed. Aggregate consumption equals total wages plus a fraction $c_{p}$ of past profits.

4. Aggregate demand is computed summing up investment and consumption.

5. Firms receive a fraction of total demand according to their market shares. They produce to accommodate their demand.

6. Individual and aggregate capacity utilization levels are computed.

7. The fraction of output devoted to investment is distributed to firms according to their individual plans. It becomes part of capital stock at time $t+1$. 


\subsection{Model equations}

Let us start our discussion by defining some microeconomic variables. ${ }^{12}$ First, we assume an investment function at the firm level which is equivalent to Equation (N-K 1):

$$
i_{i, t}=\left[g_{i, t}^{e}+\gamma_{u}\left(u_{i, t-1}-u_{n}\right)\right] k_{i, t}
$$

Here $g^{e}, u$ and $k$ are respectively firm-specific demand expectations, capacity utilization and capital stock. The target utilization rate $u_{n}$ is an exogenous parameter. Its interpretation remains therefore open. It can be seen either as coinciding with the point of lower unit costs Kurz (1986) or as the result of firm heuristics related to past demand volatility (Steindl, 1952).

Notice also that there is no lower negative bound for net investments $(i)$. This simply entails that capital depreciation is endogenous and determined by demand conditions. Firms unique goal is to achieve target utilization. In order to do so, they can always acquire or scrap the desired amount of capital stock without constraints. ${ }^{13}$ This implies the following law of motion for capital:

$$
k_{i, t}=\max \left\{k_{i, t-1}+i_{i, t-1} ; 0\right\}
$$

Well in line with the empirical evidence (Kahneman and Tversky, 1986; Gigerenzer and Todd, 1999; Hommes, 2013), agents are assumed to form expectations using simple behavioural rules and heuristics. In order to be parsimonious, here we endogenize demand expectations imposing a basic adaptive form:

$$
g_{i, t}^{e}=g_{i, t-1}^{e}+\theta\left(g_{i, t-1}-g_{i, t-1}^{e}\right)+\epsilon_{i, t} \quad \text { where: } \quad \epsilon_{i, t} \sim \mathcal{N}(0, \sigma)
$$

Hence, long-run forecasts are revised in light of past observed demand growth $(g)$. Moreover, in adjusting $g^{e}$, firms are affected by an idiosyncratic noise $\epsilon$. This introduces heterogeneity acrossagents as well as persistent fluctuations over time in individual expectations. It is outside of the scope of this paper to provide a deep theoretical justification for the presence of $\epsilon$. We instead simply want to show how micro disturbances in expectations formation may tame coordination failures, bringing back stability into the system. ${ }^{14}$ The error term can nonetheless be seen as capturing all those (firmspecific) factors affecting demand expectations, other than mechanical adaptive adjustments. ${ }^{15}$ In

\footnotetext{
${ }^{12}$ Lower case are used to distinguish micro variables from aggregate ones. The subscript $i$ refers to firms while $t$ is the time index.

${ }^{13}$ This assumption is made to make our results as transparent as possible. Imposing a fixed depreciation rates generates an asymmetry between capacity expansion (which is unbounded) and scrapping (which can only happen at a constant rate). In this way we remove potential biases, allowing capacity adjustments to be fully flexible. Notice also that assuming a variable depreciation rate, affected by demand conditions, is broadly in line with the empirical evidence (Eisner, 1972; Goolsbee, 1998). Results for the case with fixed depreciation rate are available upon request from the authors

${ }^{14}$ We leave for future extensions the possibility for agents to chose from menu of different forecasting rules (Brock and Hommes, 1997; Anufriev and Hommes, 2012; Anufriev et al., 2013a). Examples of macroeconomic models which allow for switching and rules selection are De Grauwe (2012) in a DSGE framework and Dosi et al. (2020a) for the "K+S" model. Alternatively, (Salle, 2015) introduced expectations based on neural networks. Nonetheless, we posit that dealing with heterogeneity in a more complex fashion would only strengthen our results.

${ }^{15}$ Palumbo and Trezzini (2003) provide several reasons for which the adjustment of capacity to demand should be considered as neither automatic nor instantaneous.
} 
our analysis, we will "switch on and off" the shocks to investigate different scenarios. In particular, depending on the specification of $\theta$ and $\sigma$ one can define four cases:

1. $[\boldsymbol{\theta}=\mathbf{0} ; \boldsymbol{\sigma}=\mathbf{0}]$ : Identical firms with time-invariant expectations.

2. $[\boldsymbol{\theta} \in(\mathbf{0}, \mathbf{1}) ; \boldsymbol{\sigma}=\mathbf{0}]$ : Identical firms with adaptive learning.

3. $[\boldsymbol{\theta} \in(\mathbf{0}, \mathbf{1}) ; \boldsymbol{\sigma}>\mathbf{0}]:$ Heterogeneous firms with adaptive stochastic expectations. The process for $g^{e}$ is stationary, the effect of shocks is temporary. Hence, $g^{e}$ will fluctuate around a timedrift given by the evolution of $g$.

4. $[\boldsymbol{\theta}=\mathbf{0} ; \boldsymbol{\sigma}>\mathbf{0}]$ : Heterogeneous firms with random walk expectations. The process for $g^{e}$ is $\mathrm{I}(1)$, shocks have a permanent effects while $g$ do not play any role.

Cases 1 and 2 rule out heterogeneity and will be discussed in Section 4.1. The focus of this paper is on case 3 since it describes a scenario where expectations are heterogeneous and linked to the dynamics of demand. When $\theta=0$ (case 4) $g^{e}$ degenerates to an I(1) process, expectations become purely random and disconnected from actual demand growth.

Firms are assumed to keep a fixed proportion between capital $(k)$ and labour $(l)$ :

$$
l_{i, t}=\frac{k_{i, t}}{a v}
$$

Where $a$ is labour productivity and $v$ is the capital-to-output ratio. ${ }^{16}$ Firms start the production only after they know their level of demand. ${ }^{17}$ They produce exactly to match demand, up to capacity constraints:

$$
y_{i, t}=\min \left\{A D_{t} f_{i} ; \frac{k_{i, t}}{v}\right\}
$$

Where $A D$ is total aggregate demand, $f$ stands for the individual market share and $\frac{k}{v}$ is maximum capacity output. Modelling the evolution of $f$ would imply making some other assumptions about competition and market selection mechanisms. Instead, we want to keep our model as simple as possible and therefore market shares are assumed to be constant and exogenous. In other words, simulations are performed imposing an invariant distribution of firm size. ${ }^{18}$ Nonetheless, we allow for three different specifications for the distribution of $f$ :

- Baseline: $f_{i}=1 / N \quad \forall i$.

- Pareto: $f_{i} \sim \operatorname{Pareto}(1,1)$.

- Lognormal: $f_{i} \sim \operatorname{Lognormal}(0,1)$.

\footnotetext{
${ }^{16}$ The assumption is intended to avoid problems of simultaneity which force an error in the simulation run. On the contrary, simultaneity is not a problem for the baseline model with analytic solution. Results are robust when using the hiring rule with lagged sales: $l_{i, t}=\frac{y_{i, t-1}}{a}$. They are available upon request from the authors.

${ }^{17}$ For the sake of transparency, we remove the uncertainties associated to the production process. As a consequence, we can retain from modelling inventories. In this way agents are only affected by uncertainty when undertaking investment decisions.

${ }^{18}$ Notice that an invariant distribution of size implies an identical growth rate of demand $g$ across firms.
} 
We therefore allow for a benchmark case in which firms have identical shares as well as two alternative scenarios with right-skewed distributions of size. ${ }^{19}$ Given output levels and the capital stock it is possible to compute the degree of capacity utilization as:

$$
u_{i, t}=y_{i, t} \frac{v}{k_{i, t}}
$$

We can now discuss aggregate variables. As in Equations (N-K 2) and (N-K 3) total consumption and the profit rate are given by:

$$
\begin{gathered}
C_{t}=c_{p} \Pi_{t}+w L_{t} \quad \text { Where: } \Pi=R_{t} K_{t} \\
R_{t}=\frac{m U_{t}}{v}
\end{gathered}
$$

Aggregate demand is the sum of consumption and investments:

$$
A D_{t}=C_{t}+\sum_{i=1}^{N} \max \left\{i_{i, t} ; 0\right\}
$$

Finally, average capacity utilization and national income are also obtained as:

$$
\begin{gathered}
Y_{t}=\sum_{i=1}^{N} y_{i, t}=A D_{t} \\
U_{t}=\sum_{i=1}^{N} u_{i, t} \frac{k_{i, t}}{K_{t}}=\frac{Y_{t} v}{K_{t}}
\end{gathered}
$$

\section{Results}

The stability of the system will be investigated under different scenarios. We start by assuming homogeneous expectations and show that the ABM version behaves symmetrically to the aggregative model. Then, we introduce idiosyncratic shocks and heterogeneity. In this second case H-I does not arise anymore.

In all the scenarios the system is initialized in a steady-state where each firm utilize its capacity at the desired level (see the Appendix for details). We let the economy grow in equilibrium for 10 steps and then we introduce a permanent $2 \%$ shock on wages and study the model response. ${ }^{20}$ This entails different tests for the stability of $U$ (cf. the discussion below).

\footnotetext{
${ }^{19}$ The right-skewness of the firm size distribution is a robust stylized fact of industrial dynamics Dosi (2007). Here we use two density functions widely found in the empirical literature: the Lognormal (Stanley et al., 1995) and the Pareto (Axtell, 2001). Specifically, at the beginning of the simulation a random number drawn from the assumed distribution is assigned to each firm. Market shares are then obtained by normalizing for the overall sum, in order to ensure: $\sum_{i=1}^{N} f_{i}=1$.

${ }^{20}$ We assume a permanent shift in wages to avoid any ambiguity, as common in the literature Hein et al. (2011). Results for the case of a temporary shock are available upon request. Concerning the possible effects of different sizes of the shock, we remind the reader to Section 4.4 where we test the emergence of the paradox of costs by altering the wage
} 
Parameters value are presented in Table 1. As discussed in Section 2.1, H-I is directly related to the parameters affecting expectations, i.e. $\theta$ and $\sigma$. An extensive sensitivity analysis for $\theta$ and $\sigma$ is provided in Section 4.5. The remaining parameters are simply set to ensure a realistic rate of growth for the economy (cf. the Appendix for steady-state determination). Results are obtained via Monte Carlo simulations of 500 runs.

\begin{tabular}{lll}
\hline Description & Parameter & Value \\
\hline \multicolumn{2}{l}{ Case 1: Fixed homogeneous expectations } \\
Adaptive expectations parameter & $\theta$ & 0 \\
Standard deviation (idiosyncratic shocks) & $\sigma$ & 0 \\
Fixed Demand expectation & $g^{e}$ & 0.027 \\
Case 2: Adaptive homogeneous expectations & \\
Adaptive expectations parameter & $\theta$ & 0.1 \\
Standard deviation (idiosyncratic shocks) & $\sigma$ & 0 \\
Case 3: Adaptive heterogeneous expectations & \\
Adaptive expectations parameter & $\theta$ & 0.1 \\
Standard deviation (idiosyncratic shocks) & $\sigma$ & 0.005 \\
Invariant Parameters & & \\
Target utilization rate & $u_{n}$ & 0.75 \\
Capitalists' propensity to consume & $c_{p}$ & 0.1 \\
Capacity adjustment speed & $\gamma_{u}$ & 0.03 \\
Gross profit margin rate & $m$ & 0.45 \\
Labour productivity & $a$ & 1.45 \\
Capacity-to-output ratio & $v$ & 1 \\
Number of firms & $N$ & 50 \\
Time steps & $T$ & 500 \\
Number of Monte Carlo simulations & & 500 \\
\hline
\end{tabular}

Table 1: Initial parameter configuration

\subsection{Equilibrium and Harrodian instability with homogeneous expecta- tions}

By "turning off" the shocks in Equation (3) (i.e. $\sigma=0$ ) it is possible to study a scenario with homogeneous agents. To create a parallel with the standard model we allow both for constant

shock. A higher (smaller) wage level, ceteris paribus, rises (decreases) the average $U$ across simulations. Of course, particularly large shocks may bring about strong coordination of expectations and lead to unstable patterns. As it will be discussed in Section 4.5, when coordination in expectations is particularly strong, a larger size of idiosyncratic shocks $(\sigma)$ is needed to gain stability. Notice, however, that reasonable variations of shock size can be accommodated without parallel changes in $\sigma$ (again, this is suggested by the results of Section 4.4). 
(exogenous) and adaptive expectations.

Results are reported in Figure $1 .{ }^{21}$ In the case with no learning (solid line), after the permanent shock in wages, $U$ rapidly converge to a new higher steady-state level. Instead, if expectations are adaptive (dotted line), the model is not able to reach a new equilibrium after an external perturbation. Harrodian instability emerges and $U$ increases exponentially.

Hence, our ABM version, when expectations are homogeneous, is proved to be isomorphic to the aggregate model. A balanced growth path is sustainable only insofar as agents do not revise their predictions in light of past information. This result is intuitive but important since it implies a general consistency of the ABM microfoundations adopted, allowing us to make robust comparisons with the canonical N-K model.

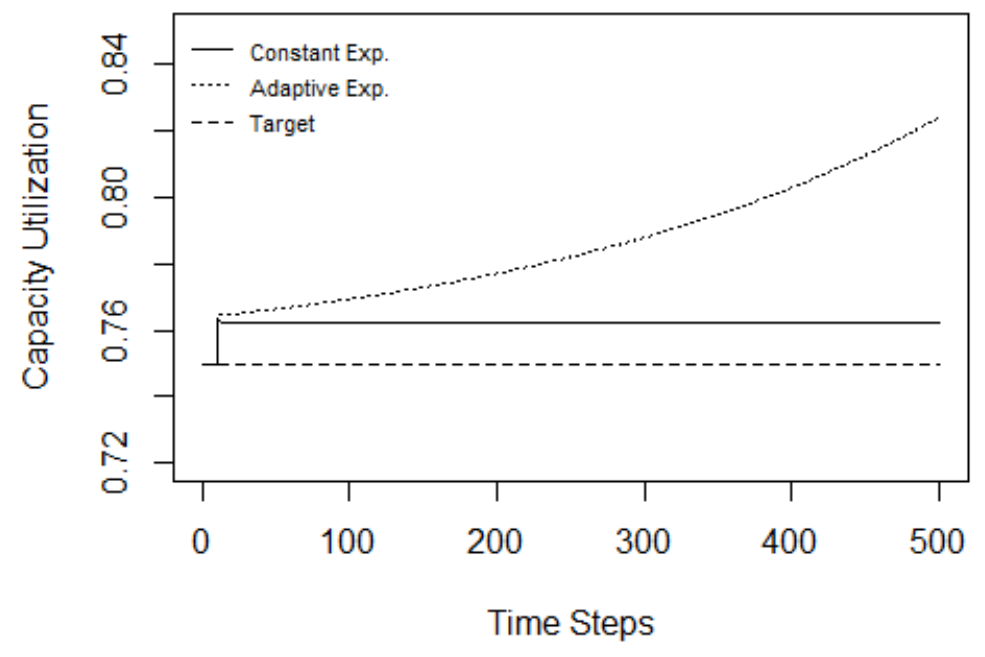

Figure 1: Model response to a permanent shock. Fixed vs. adaptive expectations

\subsection{Heterogeneous expectations}

In this section we explore the more general case with adaptive stochastic expectations. Figure 2 displays the evolution of $U$ after the shock for a single realization, adopting three different specifications of the size distribution. Imperfect adjustments of $g^{e}$ at the micro level generate, as an emergent property, endogenous fluctuations in aggregate capacity utilization. Also, $U$ evolves within realistic values and H-I does not arise. Interestingly, fluctuations do not necessary occur around the target value $u_{n}$, thus, suggesting that the endogeneity of $U$ is preserved.

\footnotetext{
${ }^{21}$ Simulations are run using Laboratory for Simulation Development (LSD). A complete description of the software is given in Valente (2008).
} 


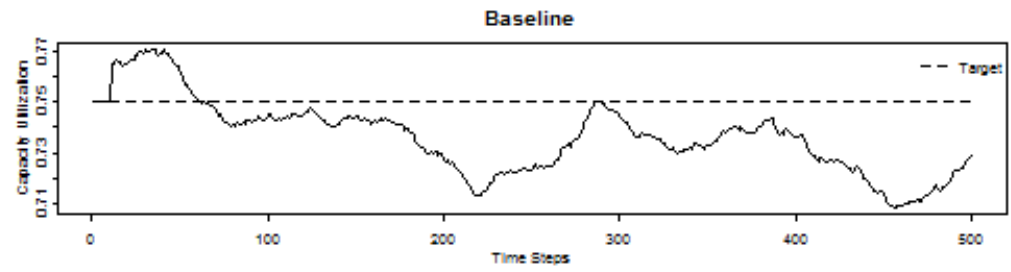

Pareto

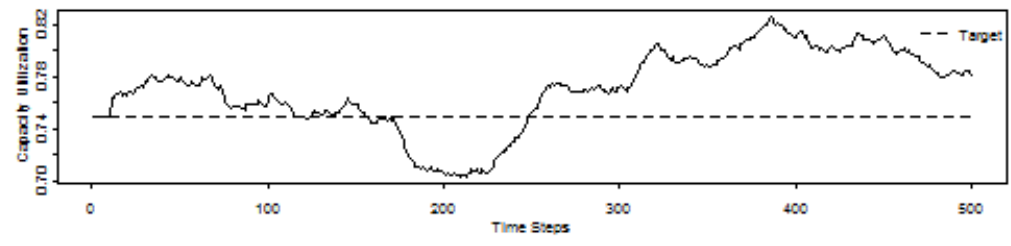

Lognormal

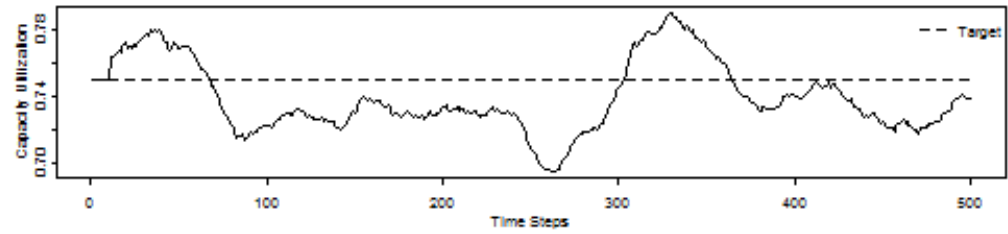

Figure 2: Model response to a permanent shock under heterogeneous expectations - Different distributions of firm size

To test whether these results are robust to different realizations of the random component, we report some Monte Carlo statistics in Table 2. Results confirm the general picture given so far: the average utilization is significantly different from $u_{n}$ while the volatility of the series is always positive. Moreover, consistently with the "granular hypothesis" (Gabaix, 2011), volatility appears to be positively related to the skewness of the firm size distribution. When market shares are Pareto-distributed, fluctuations are stronger than respectively in the Lognormal and in the baseline case.

To investigate instability we use three different measures:

- Deterministic trend: the slope of the regression $U_{t}=\alpha+\beta_{T} t$ can be used to check whether $U$ displays a trending behaviour.

- Unit root test: the augmented Dickey-Fuller test is performed to identify the presence of stochastic trends.

- Instability ratio: it is given by $x / T$. Where $x$ is the number of observations that lie above 0.95 or below 0.3 and $T$ is the total number of time steps.

By looking at $\beta_{T}$ we can conclude that capacity utilization does not exhibit any deterministic tendency to rise (fall). The instability ratio is zero on average. Therefore, across-simulations, $U$ almost never approaches either full-capacity or unrealistically low values. On the contrary, well in 
tune with recent findings in Nikiforos (2016), it is not possible to reject the unit root hypothesis for $U$. The dynamics of $U$ is thus path-dependent, being triggered by the accumulation of random shocks. Nevertheless, the presence of stochastic trends never leads to explosive patterns, as suggested by both $\beta_{T}$ and the instability ratio.

\begin{tabular}{lccccc}
\hline Size Distribution & Mean $(U)$ & Std. Dev. $(U)$ & Det. Trend slope & ADF test (p-value) & Instability Ratio \\
\hline Baseline & 0.7299 & 0.0155 & -0.0000 & 0.5072 & 0.0000 \\
& $(0.0006)$ & $(0.0002)$ & $(0.0001)$ & $(0.0123)$ & $(0.0001)$ \\
Lognormal & 0.7332 & 0.0200 & -0.0000 & 0.4952 & 0.0000 \\
& $(0.0008)$ & $(0.0003)$ & $(0.0001)$ & $(0.0123)$ & $(0.0001)$ \\
Pareto & 0.7416 & 0.0264 & -0.0000 & 0.4785 & 0.0071 \\
& $(0.0015)$ & $(0.0012)$ & $(0.0001)$ & $(0.0134)$ & $(0.0024)$ \\
\hline
\end{tabular}

Table 2: Monte Carlo Statistics for aggregate utilization. Monte Carlo standard errors are in brackets.

At this stage, two aspects are worth to be stressed. First, the presence of a unit root is an emergent property of the system. As already discussed, for $\theta>0$, micro-shocks are persistent but not permanent and individual expectations follow a stationary process. Interactions and continuous adjustments at the micro level generate an aggregate time series for $U$ which is well approximated by an I(1) specification. Second, no satisficing behaviours are assumed and the target rate of utilization remains constant during the simulation. Hence, according to our results, it can be misleading, as done in Nikiforos (2016), to interpret the trend component of $U$ as reflecting slow variations in desired utilization rates. As we will argue in the next section, secular movements in $U$ should be seen as the result of phases where microeconomic behaviours tend to weakly co-move.

\subsection{A general discussion}

In the previous sections two important results have been shown. Instability arises when agents are identical while it vanishes when micro-heterogeneity is introduced. Moreover, firms' attempts to achieve target utilization will result in a collective failure to drive $U$ towards $u_{n}$. This is a typical example of emergent property: an aggregate outcome which cannot be predicted by looking at isolated micro behaviours.

The mechanisms underlying these results are rather intuitive. Firms have to set their investment expenditures simultaneously without any information about other agents behaviour. Expectations, on the one hand, directly affect individual capital growth $(g k)$ while, on the other, contribute to overall income growth $(g)$ through aggregate demand externalities. Formally:

$$
\begin{gathered}
g k_{i, t}=f\left(g_{i, t-1}^{e}\right) \\
g_{t}=f\left(g_{1, t}^{e}, \ldots, g_{N, t}^{e}\right)
\end{gathered}
$$


From Equation (6) the growth rate of $u$ can be written as:

$$
g u_{i, t}=g_{t}-g k_{i, t}
$$

Agents interact via the macroeconomic level since their decisions determine the formation of aggregate demand. ${ }^{22}$ Each firm has a theoretical optimal expectation value $g^{e}(*)$ which, given $g$, allows to achieve target utilization. However, the value of $g$ is not given but depends on what other agents are doing and the individual optimal expectation $\left(g^{e}(*)\right)$ is affected positively by the behaviour of the other $N-1$ firms. To put it differently, the presence of aggregate demand externalities drives positive feedback between $g^{e}$ and $g$. This is reminiscent of the strategic complementarities arising in games with coordination failures (Cooper and John, 1988).

In absence of shocks and heterogeneity (cf. Section 4.1), such mutually reinforcing patterns between aggregate demand externalities and agents' expectations lead to instability. In this setting, there is perfect correlation in microeconomic behaviours. After a positive (negative) shock, expectations are continuously revised upwards (downwards) and capital stock never fully adjusts to demand. All firms will be in a persistent situation with excess (shortage of) capacity. The induced component $\gamma_{u}\left(u-u_{n}\right)$ drives a positive (negative) wedge between $g$ and $g^{e}$. As a result, all expectations will be persistently negatively (positively) biased which, in turn, entails a positive (negative) discrepancy between the growth rate of income and that of capital. Individual and aggregate utilization will therefore ever-rise up to the full-capacity limit.

Instead, idiosyncratic shocks generate heterogeneous forecasts. Agents who underestimated their demand growth $\left(g_{k}<g\right)$ will experience an increase in their utilization rates $(g u>0)$ while an inverse dynamics characterize optimistic firms $\left(g_{k}>g\right)$. Hence, at any point in time firms with $u>u_{n}$ coexist with others displaying $u<u_{n}$. This pattern can be grasped by looking at the empirical distribution of $u$ (cf. Figure 3). Indeed, micro utilization rates tend to be dispersed around the target level during the simulation. ${ }^{23}$ As a consequence, the catching-up component $\left(\gamma_{u}\left(u-u_{n}\right)\right)$ does not operate anymore as a destabilizing force, since adjustments in different directions occur contemporaneously. To put it differently, the simultaneous presence of excess capacity and underutilization brings about investment responses that are neither perfectly correlated nor uni-directional. It introduces a negative feedback in the system which breaks the self-reinforcing process underlying H-I.

Random noises are exactly responsible for continuously disrupting any tendency over equalization of expectations. They generate persistent disequilibrium at the micro level. In other words, agents never settle in a state with $u=u_{n}$. Monte Carlo statistics (cf. Table 3) using firm-level data on utilization corroborate this idea. Both the standard deviation and the average absolute deviation from $u_{n}$ are positive and significant. The mean value of pooled observations for $u$ is different from

\footnotetext{
22 This is reminiscent of late contributions embedding demand externalities and multiplier effects in a neoclassical framework (Angeletos and La'O, 2013; Beaudry et al., 2018). Even more importance to Keynesian features is given in agent-based models belonging to the " $\mathrm{K}+\mathrm{S}$ " family. Within such tradition, demand externalities and coordination issues have been recently linked to labour market dynamics in Dosi et al. (2017).

${ }^{23}$ The distribution is right censored since $u$ cannot exceed 1 (full capacity).
} 

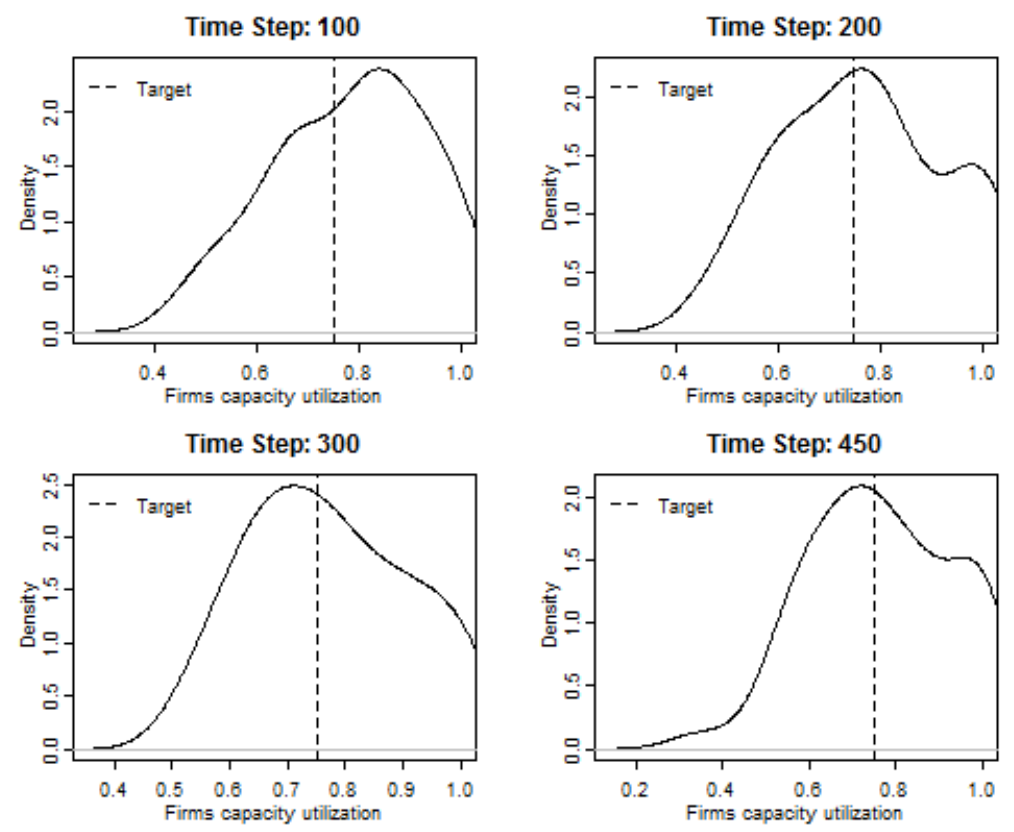

Figure 3: Firm-level utilization - Kernel density estimation

the target level, suggesting that agents do not achieve the target not even on average. ${ }^{24}$ Finally, we present the instability ratio in the fourth column. For a sample size of $N \times T$, only $20 \%$ of observations lie above or below the threshold values. The ratio is larger than the one computed using macro data (cf. Table 2). As expected, higher microeconomic turbulence tends to be partially averaged out in the process of aggregation. This aspect also suggests that a share of firms at each point in time is operating at (or close to) full capacity. Capacity constraints, therefore, provide another stabilizing mechanism insofar as they impose some upper and lower bounds to firms capacity utilization, i.e. idiosyncratic shocks can only have a negative (positive) effect for a firm which reached full (zero) capacity utilization. Nevertheless, as revealed by sensitivity analysis (cf. Section 4.5), imposing capacity constraints is not by itself sufficient to avoid Harrodian instability. Indeed, when the variance of micro shocks is too low, the system may well converge to stochastic equilibria persistently close to full (or zero) capacity utilization.

As common in evolutionary environments, a relatively stable macrodynamics emerges exactly out of persistent disequilibrium at lower levels of aggregation. Notice however that, although stability is achieved, the model can at the same time account for the cyclical behaviour of $U$. Endogenous booms and recessions arise as a result of weak correlation in investment behaviours. Expectations may, in fact, show some short-lived phases of convergence, driving both expansions and downturns.

\footnotetext{
${ }^{24}$ There is a discrepancy between the mean of $U$ (cf. Table 2) and that of $u$ (cf. Table 3). This can be explained by looking at the construction of $U$. Aggregate utilization is a weighted average of micro data. Higher weights are associated to big firms which over-accumulated capital stock and display large excess capacity. This will introduce a negative bias which instead is not present when we simply pool all the observations for $u$ and take the mean.
} 


\begin{tabular}{lcccc}
\hline Size Distribution & Mean $(u)$ & Std. Dev. $(u)$ & Abs. Dev. from $u_{n}$ & Instability Ratio \\
\hline Baseline & 0.7754 & 0.1532 & 0.1295 & 0.1933 \\
& $(0.0005)$ & $(0.0002)$ & $(0.0002)$ & $(0.0009)$ \\
Lognormal & 0.7788 & 0.1546 & 0.1327 & 0.2084 \\
& $(0.0011)$ & $(0.0003)$ & $(0.0003)$ & $(0.0021)$ \\
Pareto & 0.7772 & 0.1601 & 0.1435 & 0.2392 \\
& $(0.0026)$ & $(0.0008)$ & $(0.0013)$ & $(0.0044)$ \\
\hline
\end{tabular}

Notes: The absolute deviation from the target is computed as the average of: $\left|u_{i, t}-u_{n}\right|$.

Table 3: Monte Carlo Statistics for firm-level utilization. Monte Carlo standard errors are in brackets.

Let us now compare our strategy with the two main approaches to deal with H-I, i.e. those put forward respectively by neo-Kaleckian and Marxian authors (cf. Section 2.2). First, differently from the former, we restrain from introducing satisficing behaviours as $u_{n}$ remains an exogenous variable in our model and expectations are endogenous and realistically linked to past demand dynamics. This is confirmed by the (pooled) distribution of $g^{e}$ (cf. Figure 4) which appear to be centered around actual average demand growth. Monte Carlo statistics for $g$ and $g^{e}$ are described in Table 4 to make more robust inference. The actual growth rate of total output gravitates around a value of $4,7 \%$. Interestingly, demand expectations (third column) are not significantly different, on average, from this value and the mean prediction error (fourth column) tends to be relatively small. Such results are not surprising since, as already discussed, $g^{e}$ is modeled as an $\mathrm{AR}(1)$ process which includes $g$ as time-drift.

Nevertheless, in contrast to Marxian-inspired models, continuous expectations revisions do not lead the system to gravitate around $u_{n}$. This failure is due to the presence of spillovers and interactions, whose effects cannot be properly captured by purely aggregative models. 


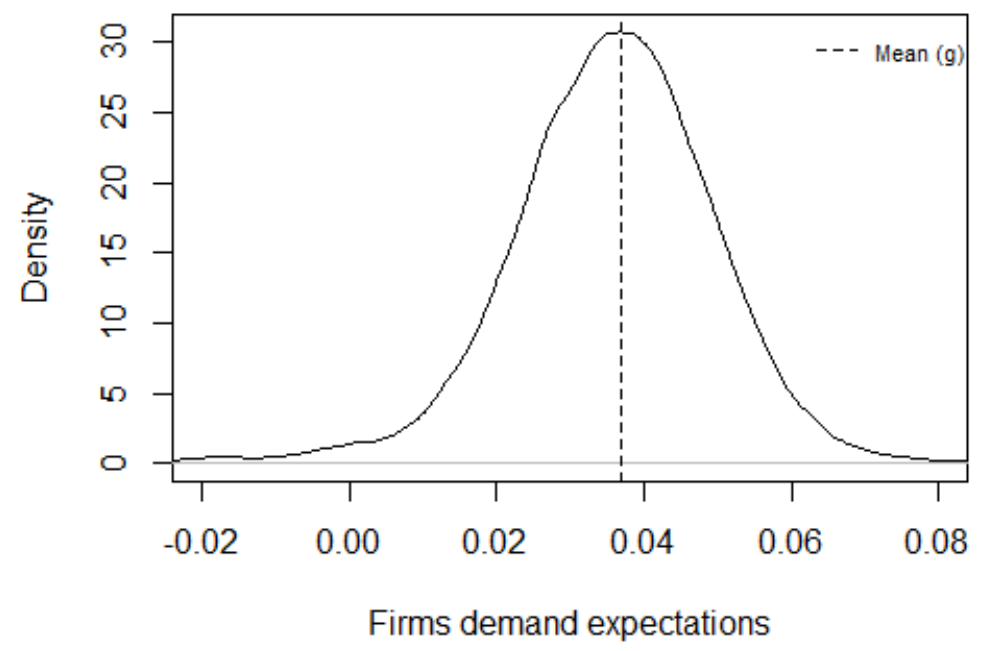

Figure 4: Firm-level expectations - Kernel density estimation

\begin{tabular}{lcccc}
\hline Size Distribution & Mean $(g)$ & Std. Dev. $(g)$ & Mean $\left(g^{e}\right)$ & Prediction Error \\
\hline Baseline & 0.0454 & 0.0154 & 0.0448 & 0.0088 \\
& $(0.0007)$ & $(0.0002)$ & $(0.0007)$ & $(0.0001)$ \\
Lognormal & 0.0472 & 0.0184 & 0.0465 & 0.0090 \\
& $(0.0010)$ & $(0.0003)$ & $(0.0010)$ & $(0.0001)$ \\
Pareto & 0.0479 & 0.0237 & 0.0471 & 0.0094 \\
& $(0.0017)$ & $(0.0006)$ & $(0.0016)$ & $(0.0001)$ \\
\hline
\end{tabular}

Notes: The prediction error is computed as the average of: $\left|g_{i, t}^{e}-g_{t}\right|$.

Table 4: Monte Carlo Statistics for demand growth rates and expectations. Monte Carlo standard errors are in brackets.

\subsection{Macroeconomic paradoxes}

In this section we test whether macroeconomic paradoxes are retained in our ABM version when heterogeneity is present. It is straightforward that comparative dynamics exercises make little sense if our variable of interest is $\mathrm{I}(1)$. We cannot expect, as for the baseline case with a steady-state solution, that permanent increases in $w$ or $c_{p}$ will lead to a new equilibrium with higher growth rates and capacity utilization. Since the process for $U$ displays a unit root, the trajectory of the 
system is driven by the accumulation of shocks. Hence, the initial positive effect of a rise in wages or in propensity to consume may be reverted for some specific realizations of the random component.

Instead of focusing on within-simulation shifts in utilization rates, macroeconomic paradoxes should be studied by means of between-simulations comparisons. To put it another way, we compare the evolution of $U$ under a $2 \%$ permanent shock (either on $w$ or $c_{p}$ at $t=10$ ), vis-à-vis a counterfactual scenario in which everything has remained unaltered. Results for a single realization are presented in Figure 5 while Figure 6 displays Monte Carlo averaged dynamics. A positive and significant difference in $U$ is found with respect to the "no shock" scenario. Under this perspective, the model presented here preserves the paradox of thrift and that of costs together with their policy implications. A boost in aggregate consumption brings about greater rates of utilization relatively to what would have happened otherwise.

A similar approach is also found in recent models assessing the impact of austerity measures in presence of investment hysteresis (Bassi and Lang, 2016). In such framework, the impact of negative demand shocks is necessarily evaluated with respect to a counterfactual world where contractionary fiscal policies have not been implemented. Our results have strong implications for the empirical tests of macroeconomic paradoxes (Stockhammer et al., 2009). In this respect, researchers should favour econometric specifications that can accommodate integrated processes while, more generally, greater attention should be given to the stationarity assumptions imposed by the econometric strategy.

Shock on Wages

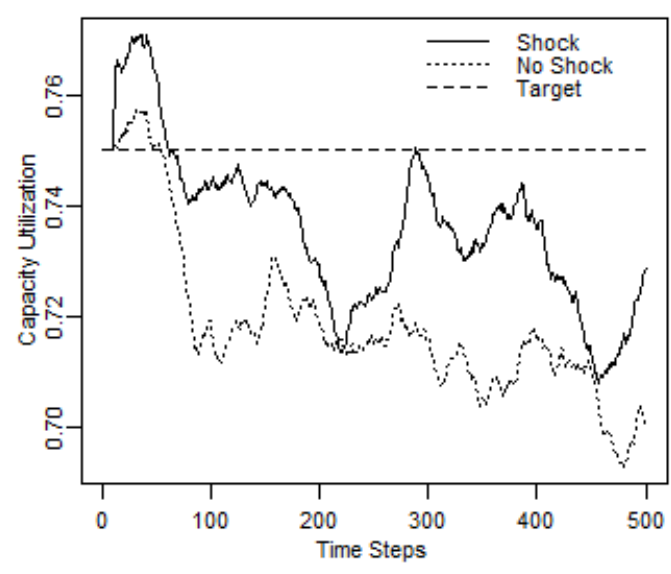

Shock on Savings

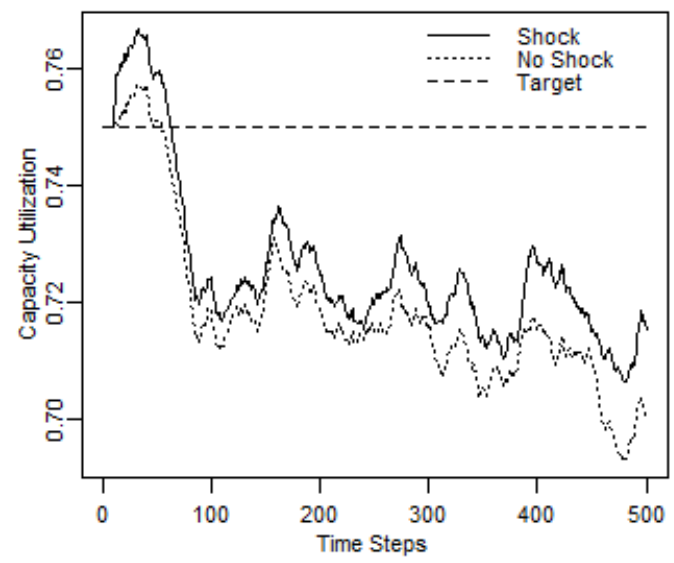

Figure 5: Capacity utilization evolution (single realization) - Shock vs. No shock scenarios 

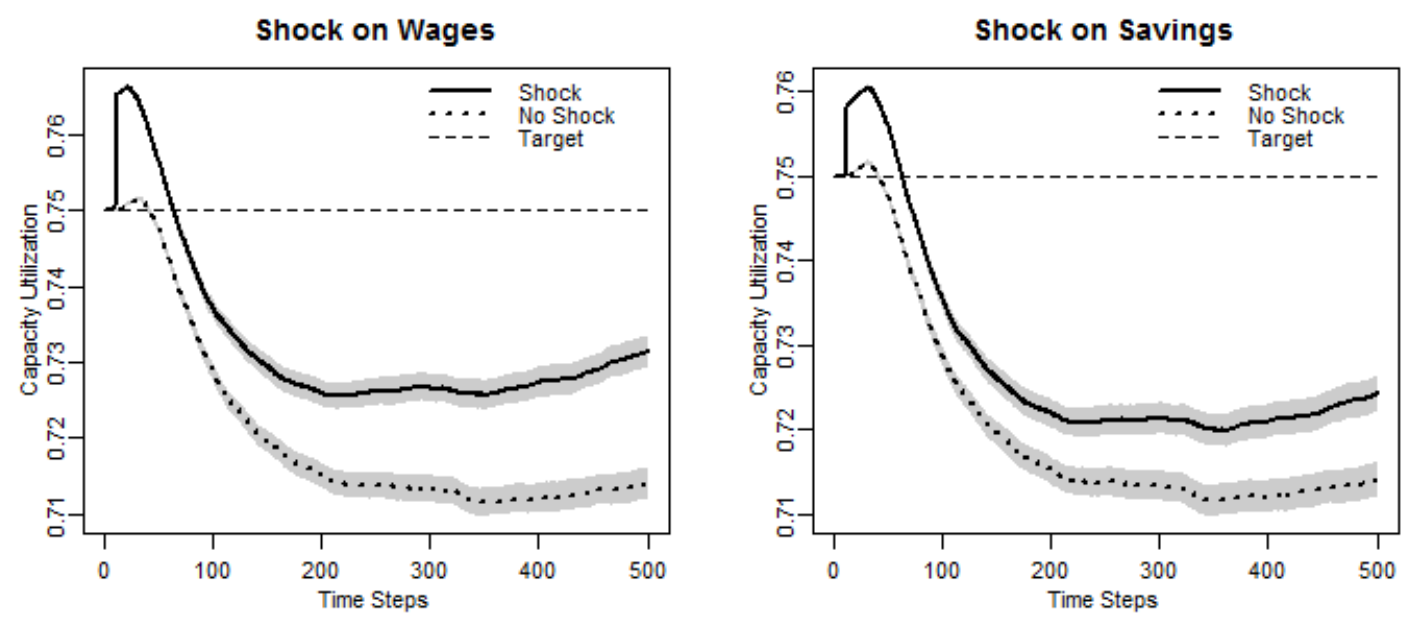

Figure 6: Monte Carlo averaged capacity utilization evolution (5\% confidence-intervals are in grey)

- Shock vs. No shock scenarios

\subsection{Sensitivity analysis}

So far we presented results for a benchmark parametrization. Now we explore their robustness under different configurations. Let us start the discussion by looking at the stability indicators. The two parameters that can be related to H-I are $\theta$ and $\sigma$ since they regulate expectations and investment behaviours. ${ }^{25}$ We explore a two-dimensional parameter space $(S)$ given by:

$$
S=\{(\theta, \sigma) \mid \theta \in[0.05,0.3] \text { and } \sigma \in[0.001,0.015]\}
$$

In Figure 7 we present contour plots showing the sensitivity of our three instability indicators for different specifications of the firm size distribution. ${ }^{26}$ Plots on the left show that we can never reject the unit root hypothesis for $U$. The estimated $p$-value of the augmented Dickey-Fuller test is always larger than 0.3. By focusing instead on the other two indicators we can make some conclusions about H-I. Upward instability emerges when $\theta$ is relatively larger than $\sigma$. In this region of the parameter space the slope of the trend is positive and the instability ratio is high. As expected, when the idiosyncratic component shrinks relatively to the adaptive one, the model converges to the case with homogeneous expectations described in Section 4.1.

When instead $\sigma$ increases excessively with respect to $\theta$, downward instability emerges. In this case, the slope of the time trend is negative and the instability ratio is high. Since $u_{n}$ is set relatively close to full capacity limit, large shocks are more likely to drive firms far below $u_{n}$ than far above. When the share of firms with excess capacity becomes extremely large, the induced

\footnotetext{
${ }^{25}$ Notice that the parameter $\gamma_{u}$ only affect Keynesian instability.

${ }^{26}$ Scatter plots are obtained as follows. First, the variable of interest is computed for all the points in a discrete subset of $S$ given by: $\{0.05,0.06, \ldots, 0.3\} \times\{0.001,0.002, \ldots, 0.015\}$. Second, we fit a local polynomial regression to explore the whole $S$.
} 
adjustment component will act as a destabilizing force and agents will converge towards ever-lower expectations.
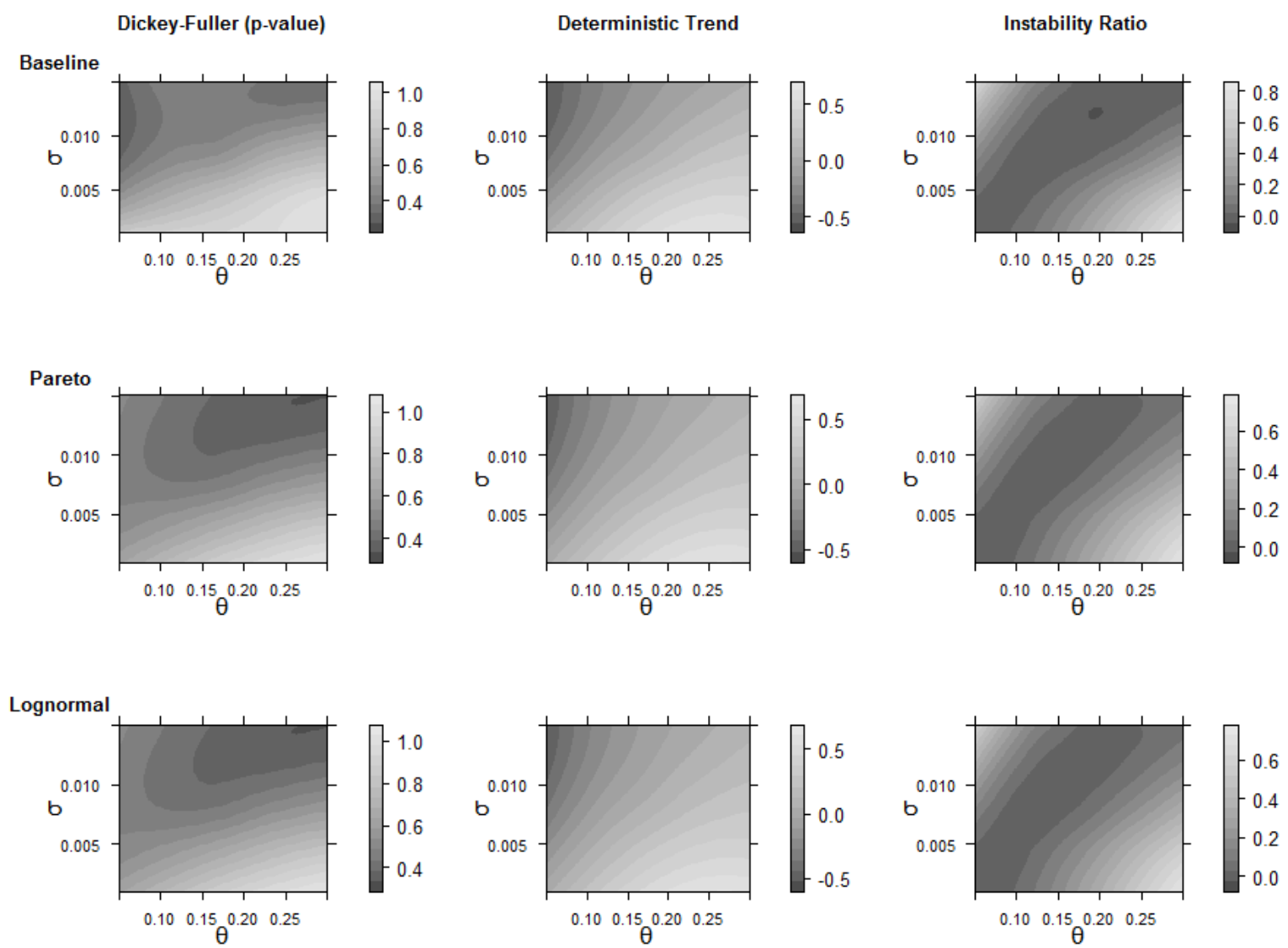

Notes: Each row display a different specification for the firm size distribution. Each column is associated to a specific instability measure. The slope of the deterministic trend is scaled up by a factor of 1000 .

Figure 7: Sensitivity analysis - Instability measures under different parameters configurations

However, it is also clear that for a significantly large portion of $S$ the model displays a nontrending behaviour and an instability ratio close to zero. In other words, stable patterns emerge when the adaptive component and the idiosyncratic one are sufficiently balanced. Sensitivity tests confirm that there is room for adaptive learning in the N-K setting. They also highlight the crucial role played by idiosyncratic errors. For a given $\sigma$, the more we move towards a purely mechanic adaptive adjustment by increasing $\theta$, the higher will be the probability to observe unstable patterns. In other words, errors and biases in predicting demand growth are needed. Purely mechanical, uni-directional adjustments cannot be sustained. This result is consistent with a large literature on learning and expectations in complex environments (Gigerenzer and Todd, 1999; Dosi et al., 2003). 
In a decentralized world characterized by heterogeneous interacting agents, individual behaviours close to rationality may lead to undesired consequences at the aggregate level. Instead, as in our case, naive agents whose decisions are largely driven by random forces, may act as stabilizers.

Another important result of the model concerns the emergence of macroeconomic paradoxes. We finally check whether this property survives to different parameter configurations. Once again, we focus on $\theta$ and $\sigma$. For each point in $S$ the following variable is computed:

$$
\Delta \bar{U}=\bar{U}^{S}-\bar{U}^{N S}
$$

Where $\bar{U}^{S}$ and $\bar{U}^{N S}$ are (Monte Carlo averaged) mean utilization respectively for a scenario with a $2 \%$ permanent shift on $w$ and for the case with no shocks. ${ }^{27}$ Figure 8 presents the evolution of $\Delta \bar{U}$ in response to parameters variations. Not surprisingly, the gap between the two scenarios becomes zero only when the volatility of expectations is extremely high. On the contrary, in normal conditions, there is a positive and significant gap in mean utilization. Therefore, we can conclude that the model robustly preserves also macroeconomic paradoxes commonly found in Keynesian economics.
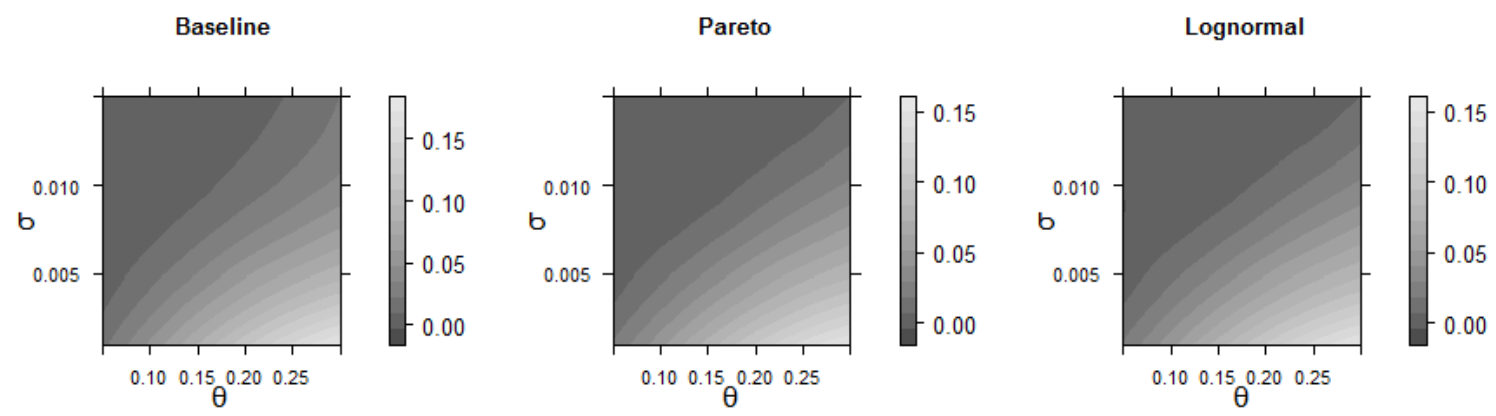

Figure 8: Sensitivity analysis - The impact of a permanent wage shock on aggregate utilization under different parameters configurations

\section{Conclusion}

In this paper we presented a simple ABM version of the standard N-K model. A parsimonious microfoundation of investment decisions has been introduced. Then, we used the model as a tool to analyze the stability properties of the system. Such approach is in line with the interpretation of Harrodian instability as a coordination failure.

We first showed that if demand expectations are homogeneous the model is isomorphic to the case with a representative firm. Then, we introduced firm-specific shocks affecting demand forecasts. Under this new specification, capacity utilization does not exhibit an explosive dynamics anymore. A non-trending process with endogenous oscillations emerges as a result of decentralized and imperfect

\footnotetext{
${ }^{27} \Delta U$ is set to zero when not significant at the $5 \%$. We do not report sensitivity analysis for a parallel shock on $c_{p}$ since it leads to the same conclusions. Nonetheless, results are available upon request.
} 
learning efforts. This suggests that dealing with heterogeneity in such a parsimonious way is already sufficient to draw alternative conclusions with respect to standard aggregate analysis.

Differently from standard approaches to deal the instability problem found in the literature, our proposal has been shown to preserve both the presence of macroeconomic paradoxes and the demand-led nature of growth. Moreover, the general robustness of our results is corroborated by sensitivity analysis presented in Section 4.

In the final part of the paper, the emphasis on idiosyncratic random prediction errors as stabilizers has been roughly linked to a series of well-known results in the field of learning in complex systems. A more sophisticated characterization of heterogeneity is however required to further investigate the issue. For instance, similarly to De Grauwe (2012) and Dosi et al. (2020a), one may be interested in adapting the heuristic switching model to the N-K setting. Symmetrically, one can introduce technical change and firm-specific productivity shocks as well as evolutionary market selection mechanisms. This will be exactly the direction of our future research.

The key contribution of this work must instead be found in its methodological proposal. We suggested that the N-K model should be extended to study expectations formation and coordination mechanisms, adopting an agent-based perspective. A similar task may provide complementary results to purely aggregative models and, as in the case presented here, it may outperform them in solving some important theoretical puzzles.

\section{Acknowledgments}

I thank Alberto Botta, Antonella Palumbo, Gabriel Porcile, Andrea Roventini, Caterina Santi, Pietro Santoleri, Anwar Shaikh, Peter Skott, Engelbert Stockhammer, Attilio Trezzini and two anonymous referees for providing useful comments and discussions. I am also grateful to participants of the $8^{\text {th }}$ Annual PhD workshop of the PKSG in Greenwich, the WEHIA 2016 conference in Castellon de la Plana and the STOREP 2016 conference in Catania. All usual disclaimers apply. The author acknowledges the support by the European Union's Horizon 2020 research and innovation programme under grant agreement No. 649186 - ISIGrowth.

\section{References}

Acemoglu, D., Carvalho, V. M., Ozdaglar, A., and Tahbaz-Salehi, A. (2012). The network origins of aggregate fluctuations. Econometrica, 80(5):1977-2016.

Allain, O. (2015). Tackling the instability of growth: a kaleckian-harrodian model with an autonomous expenditure component. Cambridge Journal of Economics, 39(5):1351-1371.

Angeletos, G.-M. and La'O, J. (2013). Sentiments. Econometrica, 81(2):739-779.

Anufriev, M., Assenza, T., Hommes, C., and Massaro, D. (2013a). Interest rate rules and macroeconomic stability under heterogeneous expectations. Macroeconomic Dynamics, 17(8):1574-1604.

Anufriev, M. and Hommes, C. (2012). Evolution of market heuristics. The Knowledge Engineering Review, 27(02):255271 . 
Anufriev, M., Hommes, C. H., and Philipse, R. H. (2013b). Evolutionary selection of expectations in positive and negative feedback markets. Journal of Evolutionary Economics, 23(3):663-688.

Ashraf, Q., Gershman, B., and Howitt, P. (2017). Banks, market organization, and macroeconomic performance: an agent-based computational analysis. Journal of Economic Behavior ES Organization, 135:143-180.

Assenza, T., Heemeijer, P., Hommes, C., and Massaro, D. (2019). Managing self-organization of expectations through monetary policy: a macro experiment. Journal of Monetary Economics.

Axtell, R. L. (2001). Zipf distribution of us firm sizes. Science, 293(5536):1818-1820.

Bassi, F. and Lang, D. (2016). Investment hysteresis and potential output: A post-keynesian-kaleckian agent-based approach. Economic Modelling, 52:35-49.

Beaudry, P., Galizia, D., and Portier, F. (2018). Reconciling hayek's and keynes' views of recessions. The Review of Economic Studies, 85(1):119-156.

Bhaduri, A. and Marglin, S. (1990). Unemployment and the real wage: the economic basis for contesting political ideologies. Cambridge journal of Economics, pages 375-393.

Blanchard, O. J. and Kiyotaki, N. (1987). Monopolistic competition and the effects of aggregate demand. The American Economic Review, pages 647-666.

Blecker, R. (1999). Kaleckian macro models for open economies. In Deprez, J. and Harvey, J. T., editors, Foundations of International Economics, pages 126-160. London: Routledge.

Blecker, R. A. (2011). Open economy models of distribution and growth. In A modern guide to Keynesian macroeconomics and economic policies, pages 215-239. Cheltenham: Edward Elgar.

Brock, W. A. and Hommes, C. H. (1997). A rational route to randomness. Econometrica, pages $1059-1095$.

Caiani, A., Godin, A., Caverzasi, E., Gallegati, M., Kinsella, S., and Stiglitz, J. E. (2016). Agent based-stock flow consistent macroeconomics: Towards a benchmark model. Journal of Economic Dynamics and Control, 69:375-408.

Carroll, C. D. (2003). Macroeconomic expectations of households and professional forecasters. the Quarterly Journal of economics, 118(1):269-298.

Committeri, M. (1986). Some comments on recent contributions on capital accumulation, income distribution and capacity utilization. Political Economy, 2(2):161-86.

Cooper, R. and John, A. (1988). Coordinating coordination failures in keynesian models. The Quarterly Journal of Economics, 103(3):441-463.

Dallery, T. and Van Treeck, T. (2011). Conflicting claims and equilibrium adjustment processes in a stock-flow consistent macroeconomic model. Review of Political Economy, 23(2):189-211.

Dawid, H., Harting, P., and Neugart, M. (2014). Economic convergence: Policy implications from a heterogeneous agent model. Journal of Economic Dynamics and Control, 44:54-80.

De Grauwe, P. (2012). Booms and busts in economic activity: A behavioral explanation. Journal of Economic Behavior \& Organization, 83(3):484-501.

Delli Gatti, D., Gallegati, M., Greenwald, B., Russo, A., and Stiglitz, J. E. (2010). The financial accelerator in an evolving credit network. Journal of Economic Dynamics and Control, 34(9):1627-1650.

Di Giovanni, J., Levchenko, A. A., and Mejean, I. (2014). Firms, destinations, and aggregate fluctuations. Econometrica, 82(4):1303-1340. 
Diamond, P. A. (1982). Aggregate demand management in search equilibrium. Journal of political Economy, $90(5): 881-894$.

Dosi, G. (2007). Statistical regularities in the evolution of industries: A guide through some evidence and challenges for the theory. In Malerba, F. and Brusoni, S., editors, Perspectives on innovation, pages 1110-1121. Cambridge: Cambridge University Press.

Dosi, G., Fagiolo, G., Napoletano, M., and Roventini, A. (2013). Income distribution, credit and fiscal policies in an agent-based keynesian model. Journal of Economic Dynamics and Control, 37(8):1598-1625.

Dosi, G., Fagiolo, G., Napoletano, M., Roventini, A., and Treibich, T. (2015). Fiscal and monetary policies in complex evolving economies. Journal of Economic Dynamics and Control, 52:166-189.

Dosi, G., Fagiolo, G., and Roventini, A. (2010). Schumpeter meeting keynes: A policy-friendly model of endogenous growth and business cycles. Journal of Economic Dynamics and Control, 34(9):1748-1767.

Dosi, G., Marengo, L., and Fagiolo, G. (2003). Learning in evolutionary environments. Working paper 2003/20, Laboratory of Economics and Management (LEM), Sant'Anna School of Advanced Studies.

Dosi, G., Napoletano, M., Roventini, A., Stiglitz, J. E., and Treibich, T. (2020a). Rational heuristics? expectations and behaviors in evolving economies with heterogeneous interacting agents. Economic Inquiry, 58(3):1487-1516.

Dosi, G., Napoletano, M., Roventini, A., and Treibich, T. (2019a). Debunking the granular origins of aggregate fluctuations: from real business cycles back to keynes. Journal of Evolutionary Economics, 29(1):67-90.

Dosi, G., Pereira, M. C., Roventini, A., and Virgillito, M. E. (2017). When more flexibility yields more fragility: the microfoundations of keynesian aggregate unemployment. Journal of Economic Dynamics and Control, 81:162-186.

Dosi, G., Roventini, A., and Russo, E. (2019b). Endogenous growth and global divergence in a multi-country agentbased model. Journal of Economic Dynamics and Control, 101:101-129.

Dosi, G., Roventini, A., and Russo, E. (2020b). Public policies and the art of catching up: matching the historical evidence with a multi-country agent-based model. Working paper 2020/10, Laboratory of Economics and Management (LEM), Sant'Anna School of Advanced Studies.

Duménil, G. and Lévy, D. (1999). Being keynesian in the short term and classical in the long term: The traverse to classical long-term equilibrium. The Manchester School, 67(6):684-716.

Dutt, A. K. (1984). Stagnation, income distribution and monopoly power. Cambridge journal of Economics, 8(1):2540 .

Dutt, A. K. (1997). Equilibrium, path dependence and hysteresis in post-keynesian models. In Arestis, P., Palma, G., and Malcom, S., editors, Markets, Unemployment, and Economic Policy, volume 2, pages 238-253. London: Routledge.

Eisner, R. (1972). Components of capital expenditures: Replacement and modernization versus expansion. The Review of Economics and Statistics, pages 297-305.

Fagiolo, G. and Roventini, A. (2012). Macroeconomic policy in dsge and agent-based models. Revue de l'OFCE, 124(5):67-116.

Fagiolo, G. and Roventini, A. (2017). Macroeconomic policy in dsge and agent-based models redux: New developments and challenges ahead. Journal of Artificial Societies 8 Social Simulation, 20(1).

Gabaix, X. (2011). The granular origins of aggregate fluctuations. Econometrica, 79(3):733-772. 
Gibson, B. and Setterfield, M. (2018). Real and financial crises in the keynes-kalecki structuralist model: An agentbased approach. Metroeconomica, 69(3):566-592.

Gigerenzer, G. and Todd, P. M. (1999). Simple heuristics that make us smart. Oxford: Oxford University Press.

Goolsbee, A. (1998). The business cycle, financial performance, and the retirement of capital goods. Review of Economic Dynamics, 1(2):474-496.

Guerini, M., Napoletano, M., and Roventini, A. (2018). No man is an island: The impact of heterogeneity and local interactions on macroeconomic dynamics. Economic Modelling, 68:82-95.

Harrod, R. F. (1939). An essay in dynamic theory. The economic journal, 49(193):14-33.

Hein, E. (2007). Interest rate, debt, distribution and capital accumulation in a post-kaleckian model. Metroeconomica, $58(2): 310-339$.

Hein, E., Lavoie, M., and van Treeck, T. (2011). Some instability puzzles in kaleckian models of growth and distribution: a critical survey. Cambridge Journal of Economics, 35(3):587-612.

Hein, E., Lavoie, M., and Van Treeck, T. (2012). Harrodian instability and the 'normal rate'of capacity utilization in kaleckian models of distribution and growth—a survey. Metroeconomica, 63(1):139-169.

Hein, E. and Van Treeck, T. (2010). Financialisation and rising shareholder power in kaleckian/post-kaleckian models of distribution and growth. Review of Political Economy, 22(2):205-233.

Hein, E. and Vogel, L. (2008). Distribution and growth reconsidered: empirical results for six oecd countries. Cambridge journal of Economics, 32(3):479-511.

Hicks, J. R. (1950). A Contribution to the Theory of the Trade Cycle. Oxford: The Clarendon Press;.

Hommes, C. (2011). The heterogeneous expectations hypothesis: Some evidence from the lab. Journal of Economic dynamics and control, 35(1):1-24.

Hommes, C. (2013). Behavioral rationality and heterogeneous expectations in complex economic systems. Cambridge: Cambridge University Press.

Hommes, C., Sonnemans, J., Tuinstra, J., and Van de Velden, H. (2005). Coordination of expectations in asset pricing experiments. The Review of Financial Studies, 18(3):955-980.

Howitt, P. (2006a). Coordination issues in long-run growth. Handbook of computational economics, 2:1605-1624.

Howitt, P. (2006b). The microfoundations of the keynesian multiplier process. Journal of Economic Interaction and Coordination, 1(1):33-44.

Kahneman, D. and Tversky, A. (1986). Rational choice and the framing of decisions. Journal of business, 59(4):251278 .

Kaldor, N. (1957). A model of economic growth. The economic journal, 67(268):591-624.

Kurz, H. D. (1986). Normal positions and capital utilization. Political Economy, 2(1):37-54.

Lamperti, F., Dosi, G., Napoletano, M., Roventini, A., and Sapio, A. (2018). Faraway, so close: coupled climate and economic dynamics in an agent-based integrated assessment model. Ecological Economics, 150:315-339.

Lavoie, M. (1995). The kaleckian model of growth and distribution and its neo-ricardian and neo-marxian critiques. Cambridge Journal of Economics, 19(6):789-818. 
Lavoie, M. (2014). Post-Keynesian economics: new foundations. Cheltenham: Edward Elgar Publishing.

Leijonhufvud, A. (1976). On Keynesian Economics and the Economics of Keynes: A study in monetary theory. Oxford: Oxford University Press.

Luìs, G., Giulio, G., and Gabriel, P. (2020). Environmental innovations, income distribution, international competitiveness and environmental policies: a kaleckian growth model with a balance of payments constraint. Structural Change and Economic Dynamics, 53:16-25.

Massaro, D. (2013). Heterogeneous expectations in monetary dsge models. Journal of Economic Dynamics and Control, 37(3):680-692.

Nikiforos, M. (2016). On the 'utilisation controversy': a theoretical and empirical discussion of the kaleckian model of growth and distribution. Cambridge journal of economics, 40(2):437-467.

Palumbo, A. and Trezzini, A. (2003). Growth without normal capacity utilization. European Journal of the History of Economic Thought, 10(1):109-135.

Pasinetti, L. L. (1962). Rate of profit and income distribution in relation to the rate of economic growth. The Review of Economic Studies, 29(4):267-279.

Pfajfar, D. and Santoro, E. (2010). Heterogeneity, learning and information stickiness in inflation expectations. Journal of Economic Behavior \& Organization, 75(3):426-444.

Popoyan, L., Napoletano, M., and Roventini, A. (2017). Taming macroeconomic instability: Monetary and macroprudential policy interactions in an agent-based model. Journal of Economic Behavior 63 Organization, 134:117140 .

Riccetti, L., Russo, A., and Gallegati, M. (2015). An agent based decentralized matching macroeconomic model. Journal of Economic Interaction and Coordination, 10(2):305-332.

Riccetti, L., Russo, A., and Gallegati, M. (2016). Financialisation and crisis in an agent based macroeconomic model. Economic Modelling, 52:162-172.

Robinson, J. (1956). The Accumulation of Capital. London: Macmillan.

Rowthorn, B. (1981). Demand, real wages and economic growth. London: Thames Polytechnics.

Russo, E., Foster-McGregor, N., and Verpagen, B. (2019). Characterizing growth instability: new evidence on unit roots and structural breaks in long run time series. Working paper series 2019/29, Laboratory of Economics and Management (LEM), Scuola Superiore Sant'Anna, Pisa, Italy.

Salle, I., Yıldızoğlu, M., and Sénégas, M.-A. (2013). Inflation targeting in a learning economy: An abm perspective. Economic Modelling, 34:114-128.

Salle, I. L. (2015). Modeling expectations in agent-based models - an application to central bank's communication and monetary policy. Economic Modelling, 46:130-141.

Seppecher, P. and Salle, I. (2015). Deleveraging crises and deep recessions: a behavioural approach. Applied Economics, 47(34-35):3771-3790.

Setterfield, M. and Budd, A. (2011). A keynes-kalecki model of cyclical growth with agent-based features. In Arestis, P., editor, Microeconomics, Macroeconomics and Economic Policy, pages 228-250. London: Palgrave Macmillan.

Shaikh, A. (2009). Economic policy in a growth context: a classical synthesis of keynes and harrod. Metroeconomica, $60(3): 455-494$. 
Skott, P. (2012). Theoretical and empirical shortcomings of the kaleckian investment function. Metroeconomica, 63(1):109-138.

Stanley, M. H., Buldyrev, S. V., Havlin, S., Mantegna, R. N., Salinger, M. A., and Stanley, H. E. (1995). Zipf plots and the size distribution of firms. Economics letters, 49(4):453-457.

Steindl, J. (1952). Maturity and stagnation in American capitalism. London: Monthly Review Press.

Stockhammer, E., Onaran, Ö., and Ederer, S. (2009). Functional income distribution and aggregate demand in the euro area. Cambridge journal of Economics, 33(1):139-159.

Tversky, A. and Kahneman, D. (1974). Judgment under uncertainty: Heuristics and biases. science, 185(4157):11241131 .

Valente, M. (2008). Laboratory for simulation development: Lsd. Working paper 2008/12, Laboratory of Economics and Management (LEM), Sant'Anna School of Advanced Studies. 


\section{Appendix. Equilibrium solution and initialization}

Our strategy is to initialize the model in a steady state with desired utilization and no bias in expectations. In this way we can explore whether the system is able to restore the equilibrium after an exogenous disturbance. A stady-state solution for the model can be derived when firm expectations are exogenous and identical. Simple aggregation of investment equations (cf. Eq. 1) leads to:

$$
\frac{I_{t}}{K_{t}}=g^{e}+\gamma_{u}\left(U_{t-1}-u_{n}\right)
$$

This formula is the discrete-time version of Equation (N-K 1). Symmetrically, total employment is obtained aggregating hiring decisions (cf. Eq. 4):

$$
L_{t}=\frac{K_{t}}{a v}
$$

The latter two relations form together with Equations (7)-(11) a dynamical system which has an equilibrium solution for $U$ given by:

$$
U^{*}=\frac{g^{e}-\gamma_{u} u_{n}+W /(a v)}{(1 / v)\left(1-c_{p} m\right)-\gamma_{u}}
$$

Notice that the equilibrium is slightly different from the standard one of the baseline model. This is due to the different hiring rule adopted here which is chosen for analytic convenience in order to avoid problems of simultaneity during the simulation. As a final step we compute the value of $g^{e}$ which ensures $U^{*}=u_{n}$. Therefore we have:

$$
g^{e}=\frac{u_{n}\left(1-c_{p} m\right)-W / a}{v}
$$

Using this condition we set parameter values. Table 1 reports the benchmark parameter configuration. The values of $\theta$ and $\sigma$ depend on the scenario studied.

Finally, individual demand and capital stock are initialized in order to guarantee target utilization for each firm at $t=0$. 